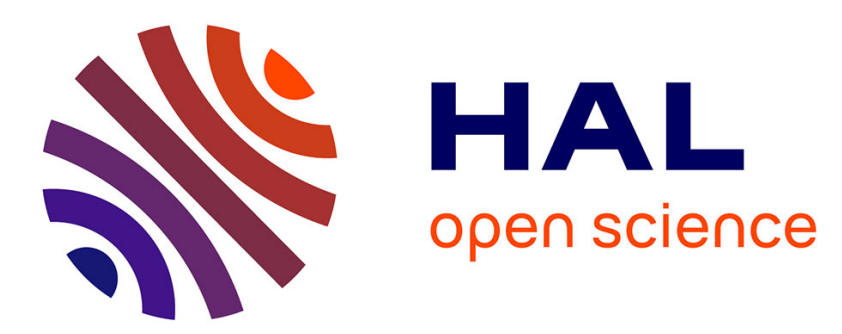

\title{
Molecular dynamics simulations of oxygen diffusion in GdBaCo2O5.5
}

\author{
J. Hermet, G. Geneste, G. Dezanneau
}

\section{To cite this version:}

J. Hermet, G. Geneste, G. Dezanneau. Molecular dynamics simulations of oxygen diffusion in GdBaCo2O5.5. Applied Physics Letters, 2010, 97, pp.174102. 10.1063/1.3504250 . hal-00580593

\section{HAL Id: hal-00580593 \\ https://hal.science/hal-00580593}

Submitted on 7 Apr 2011

HAL is a multi-disciplinary open access archive for the deposit and dissemination of scientific research documents, whether they are published or not. The documents may come from teaching and research institutions in France or abroad, or from public or private research centers.
L'archive ouverte pluridisciplinaire HAL, est destinée au dépôt et à la diffusion de documents scientifiques de niveau recherche, publiés ou non, émanant des établissements d'enseignement et de recherche français ou étrangers, des laboratoires publics ou privés. 


\title{
Molecular dynamics simulations of oxygen diffusion in $\mathrm{GdBaCo}_{2} \mathrm{O}_{5.5}$
}

\author{
J. Hermet, ${ }^{1}$ G. Geneste, ${ }^{2}$ and G. Dezanneau ${ }^{1, a)}$ \\ ${ }^{1}$ Laboratoire Structures, Propriétés et Modélisation des Solides, Ecole Centrale Paris, CNRS-UMR 8580, \\ Grande voie des vignes 92295, Châtenay-Malabry Cedex, France \\ ${ }^{2}$ CEA, DAM, DIF, F-91297 Arpajon, France
}

(Received 3 June 2010; accepted 27 September 2010; published online 25 October 2010)

\begin{abstract}
The mechanisms of oxygen diffusion in $\mathrm{GdBaCo}_{2} \mathrm{O}_{5.5}$ compound are investigated by molecular dynamics simulations. The results confirm that diffusion is mainly bidimensional with oxygen moving in the $(\mathrm{a}, \mathrm{b})$ plane while diffusion along the $\mathrm{c}$ axis is much more difficult. Between 1000 and $1600 \mathrm{~K}$, the activation energy for diffusion is about $0.6 \mathrm{eV}$, close to experimental values. Going deeper inside the oxygen diffusion mechanism, we see that this diffusion occurs mainly in the cobalt planes while most of the oxygen vacancies are kept in the Gd planes. Analysis of oxygen motions show that Gd planes can be seen as source-sink for the oxygen vacancies rather than as fast pathways. (C) 2010 American Institute of Physics. [doi:10.1063/1.3504250]
\end{abstract}

The main issue in solid oxide fuel cells (SOFC) technology is to lower the operating temperature ${ }^{1}$ in the range $500-750{ }^{\circ} \mathrm{C}$. Due its high activation energy process, the cathode becomes a major source of losses at low temperature. ${ }^{2}$ Recent experiments show the suitability of $\mathrm{GdBaCo}_{2} \mathrm{O}_{5.5+\mathrm{x}}$ as a cathode material for intermediate temperature SOFCs. ${ }^{3,4}$ To understand the particularities of this promising material, we study here the oxygen diffusion in $\mathrm{GdBaCo}_{2} \mathrm{O}_{5.5}$ using molecular dynamics (MD) simulations.

$\mathrm{GdBaCo}_{2} \mathrm{O}_{5.5+\mathrm{x}}$ is a double perovskite compound with $\mathrm{Gd}$ and $\mathrm{Ba}$ cations alternating on the $\mathrm{A}$ site along the $\mathrm{c}$ axis, leading to a tetragonal symmetry at high temperature. It generally contains oxygen vacancies and mixed valency on cobalt site. The diffusion of oxygen species is far from being understood in these compounds even if the presence of oxygen vacancies in the Gd plane, as found from neutron diffraction, ${ }^{5}$ suggested preferential diffusion in this atomic plane. We thus performed here MD simulations to get deeper inside the oxygen diffusion mechanism. All simulations were run with the DLPOLY $\operatorname{code}^{6-8}$ using a supercell of $4 \times 4 \times 2$ unit cells (containing 304 atoms and 16 vacancies). This gives roughly the same size for the supercell box in all directions due to the doubling of the $\mathrm{c}$ parameter in the pristine structure. Interactions between ions were described by a long-range Coulombic term calculated by Ewald summation, and a short-range Buckingham pair potential. For Coulombic interactions, the formal charges $+2,+3,+3$, and -2 were used, respectively, for $\mathrm{Ba}, \mathrm{Gd}, \mathrm{Co}$, and $\mathrm{O}$ ions. The use of formal ionic charge was shown to represent correctly the dynamic features of atoms in most oxide compounds. ${ }^{9-12}$ The Buckingham potential is described by the following:

$$
\varphi_{i j}(r)=A_{i j} \exp \left(-\frac{r}{\rho_{i j}}\right)-\frac{C_{i j}}{r^{6}}
$$

where $r$ is the distance between the atoms $i$ and $j$, and $A_{i j}, \rho_{i j}$, and $C_{i j}$ are potential parameters specific to each ion pair whose values are given in Table I. Two sets of potentials were used which were previously validated in MD simulations of cobaltite compounds. For the set no. 1, we used the

\footnotetext{
${ }^{\text {a) }}$ Author to whom correspondence should be addressed. Electronic mail: guilhem.dezanneau@ecp.fr.
}

potentials from Fisher et $a .^{9}$ for $\mathrm{Ba}-\mathrm{O}, \mathrm{Co}-\mathrm{O}, \mathrm{O}-\mathrm{O}$ interactions, and we determined the parameters for gadoliniumoxygen pair by fitting structural data of $\mathrm{Gd}_{2} \mathrm{O}_{3}$. For the second set, we directly used the interatomic potentials from Rupasov et al., ${ }^{10}$ Busker et al., ${ }^{11}$ and Minervini et al. ${ }^{12}$ The potentials were tested by performing energy minimizations with the GULP software ${ }^{13}$ at a temperature of $0 \mathrm{~K}$ on a 4 $\times 4 \times 6$ supercell with vacancies located in the Gd plane. As results, the calculated cell $a=b$ and $c$ parameters expressed for a pseudotetragonal double perovskite cell, were 3.76(1) $\AA$ and 7.58(1) $\AA$ for the potentials set no. 1, and 3.87(3) $\AA$ and 7.71(6) $\AA$ for potentials set no. 2. These values are close to those extrapolated to $0 \mathrm{~K}$ from high temperature measurements $(\mathrm{a}=\mathrm{b}=3.85337 \AA$ and $\mathrm{c}=7.5318 \AA)$.

The system was first equilibrated at 1000, 1200, 1400, and $1600 \mathrm{~K}$ and at zero pressure for 10000 time steps (with a time step of $2 \mathrm{fs}$ ) in the isothermal-isobaric (NPT) ensemble with Nosé-Hoover thermostat. Then 100000 time steps allowed to find the equilibrium lattice parameters. While for the set of potentials no. 1, the tetragonal high temperature structure was maintained with cell parameters close to experimental values, for the set no. 2, a dramatic increase in the $c$ cell parameter was observed leading to a collapse of the structure. In this case, we thus used a

TABLE I. Sets 1 and 2 of Buckingham interatomic potential parameters for $\mathrm{GdBaCo}_{2} \mathrm{O}_{5.5}$.

\begin{tabular}{lcccc}
\hline \hline Interaction & & $\begin{array}{c}\mathrm{A} \\
(\mathrm{eV})\end{array}$ & $\begin{array}{c}\rho \\
(\AA)\end{array}$ & $\begin{array}{c}\mathrm{C} \\
\left(\mathrm{eV} \AA^{-6}\right)\end{array}$ \\
\hline $\mathrm{Ba}^{2+} \ldots \mathrm{O}^{2-}$ & Set $1^{\mathrm{a}}$ & 1214.4 & 0.3537 & 0.0 \\
& Set $2^{\mathrm{b}}$ & 905.70 & 0.3976 & 0.0 \\
$\mathrm{Gd}^{3+} \ldots \mathrm{O}^{2-}$ & Set $1^{\mathrm{c}}$ & 1458.38 & 0.3522 & 0.0 \\
& Set $2^{\mathrm{d}}$ & 1885.75 & 0.3399 & 20.34 \\
$\mathrm{Co}^{3+} \ldots \mathrm{O}^{2-}$ & Set $1^{\mathrm{a}}$ & 1329.82 & 0.3087 & 0.0 \\
& Set $2^{\mathrm{e}}$ & 1226.32 & 0.3087 & 0.0 \\
$\mathrm{O}^{2-} \ldots \mathrm{O}^{2-}$ & Set $1^{\mathrm{a}}$ & 22764.3 & 0.149 & 43.0 \\
& Set $2^{\mathrm{e}}$ & 9547.96 & 0.2192 & 32.0 \\
\hline \hline
\end{tabular}

${ }^{\mathrm{a}}$ Fischer et $a .^{8}$

${ }^{\mathrm{b}}$ Busker et al. ${ }^{10}$

${ }^{\mathrm{c}}$ This study.

${ }^{\mathrm{d}}$ Minervini, Zacate, and Grimes. ${ }^{11}$

${ }^{\mathrm{e}}$ Rupasov et al. ${ }^{9}$ 


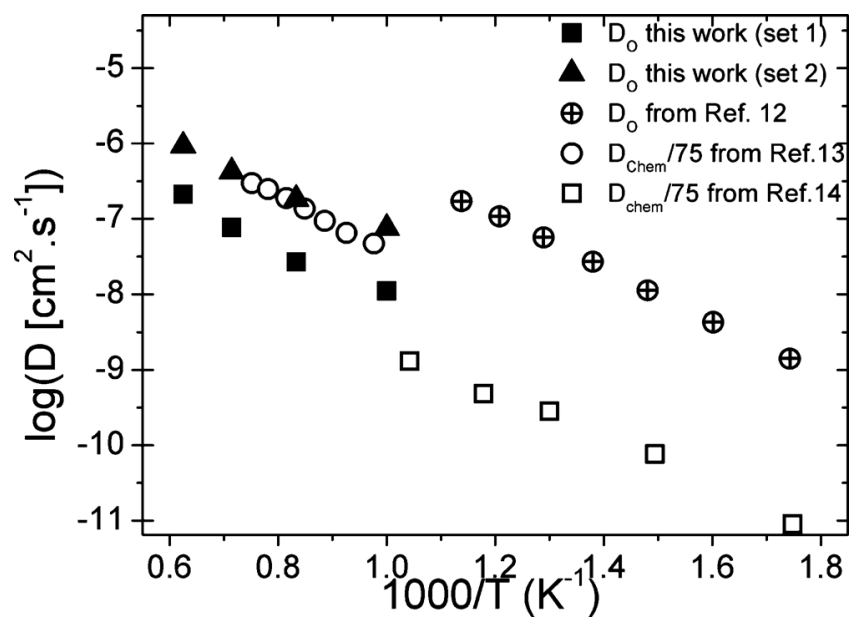

FIG. 1. Arrhenius plot of oxygen diffusivity in $\mathrm{GdBaCo}_{2} \mathrm{O}_{5,5}$ : simulations (triangles) and comparison to diffusion coefficient as obtained from oxygen exchange (Ref. 12) and from oxygen chemical diffusion oxygen corrected by thermodynamic factor (Refs. 13 and 14).

DL_POLY isotropic option during NPT simulations for which, the $a=b$ and $c$ parameters are allowed to vary in a non independent way. Then, 100000 times steps were performed in the canonical ensemble (NVT) with Nosé-Hoover thermostat, keeping the lattice constants at their previously determined equilibrated values, and finally the diffusion properties were studied in the microcanonical ensemble (NVE), for $2 \times 10^{6}$ time steps (up to $5 \times 10^{6}$ time steps). The calculated thermal expansion was $15.2 \times 10^{-6} \mathrm{~K}^{-1}$ for set no. 1 , while it was only $8.8 \times 10^{-6} \mathrm{~K}^{-1}$ for set no. 2 . The first value is very close to the one experimentally found by Tarancón et al. ${ }^{4}$ of $16.4 \times 10^{-6} \mathrm{~K}^{-1}$ for $\mathrm{GdBaCo}_{2} \mathrm{O}_{5+\mathrm{x}}$. This result would indicate that set no. 2 is probably not fully adapted for such simulations.

The oxygen diffusivity was determined from the evolution of the mean square displacement as a function of time at different temperatures using the Einstein's law. The values of $D$ are represented in the Arrhenius plot of Fig. 1. We also plot the oxygen tracer diffusion coefficient as determined from Tarancon et al. ${ }^{12}$ These two coefficients could be directly compared, neglecting the evolution of oxygen composition with temperature. We also present in Fig. 1 the chemical diffusion coefficients as determined from relaxation measurements to which was applied a correction. Indeed, the chemical diffusion coefficient was divided by the thermodynamic factor set to 75 , corresponding to the value obtained from the oxygen content in GBCO in the range $950-1050{ }^{\circ} \mathrm{C}^{15}$ From our simulations, the oxygen transport can be described by an Arrhenius law with an activation energy of $0.67 \mathrm{eV}$ and $0.56 \mathrm{eV}$, respectively, for sets 1 and 2 . Theses values reasonably compare with the value of $0.60 \mathrm{eV}$ found from isotope exchange. ${ }^{14}$ They are also close to the values of oxygen chemical diffusion activation energies of $0.66 \mathrm{eV}$ and $0.77 \mathrm{eV}$ found, respectively, by Taskin et al. ${ }^{16}$ and Choi et al. ${ }^{17}$ from mass and conductivity relaxation measurements. Nevertheless, all the diffusion coefficients presented in Fig. 1 spread over several orders of magnitude for a same temperature, underlining the difficulty to determine experimentally the oxygen diffusion coefficient.

MD simulations also allow a deeper understanding of diffusion mechanism. Figure 2 compares the mean square displacement of oxygen along the c-axis and in the a-b plane

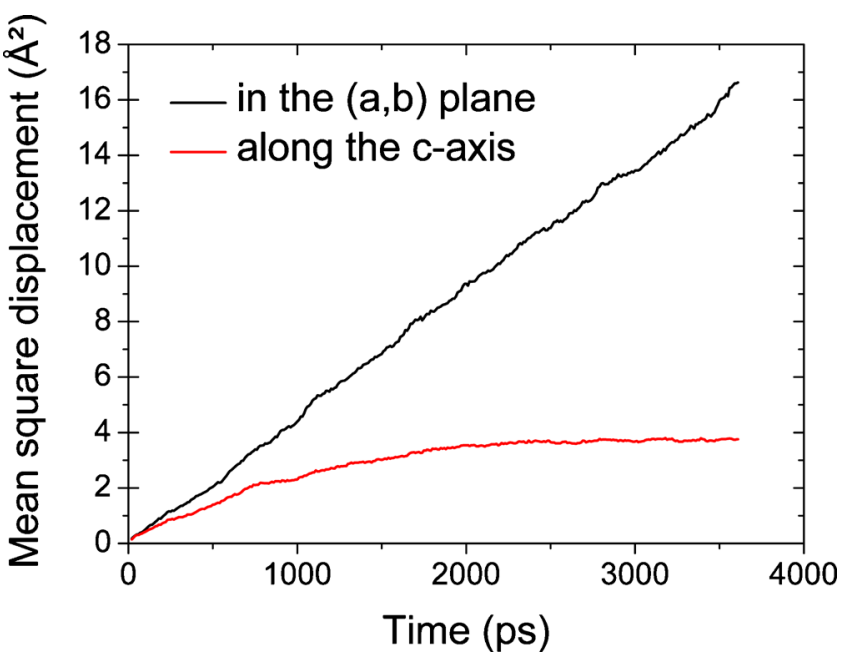

FIG. 2. (Color online) Mean square displacement of oxygen in the $a-b$ plane and along the $c$-axis at $1400 \mathrm{~K}$.

at $1400 \mathrm{~K}$. Oxygen atoms mostly diffuse in the a-b plane with a diffusivity of $1.1 \times 10^{-7} \mathrm{~cm}^{2} \mathrm{~s}^{-1}$. This diffusivity is almost ten times higher than the one found along the c-axis of $1.3 \times 10^{-8} \mathrm{~cm}^{2} \mathrm{~s}^{-1}$. This anisotropic diffusion can be explained by the absence of oxygen vacancies in the barium planes, making the efficient diffusion of oxygen vacancies across Ba planes difficult.

Barium planes logically do not contain oxygen vacancies. As foreseen from previous neutron diffraction studies, vacancies are mainly located in the gadolinium planes ( $\sim 95 \%)$, but significant amount of them is also in the cobalt planes $(\sim 5 \%)$. When studying the individual displacements of oxygen atoms, we observe that they spend most of their time in the cobalt planes and occasionally hop into gadolinium planes (where they stay only for a few picoseconds while they can remain up to some nanoseconds in cobalt planes). Figure 3 presents the oxygen density (a) in (001) cobalt planes and (b) in (100) cobalt planes. Figure 3(b) confirms that oxygen atoms in barium planes stay at the same position and do not diffuse in the neighboring cobalt planes. Besides, a count of the oxygen hops shows that oxygen atoms make roughly three times more jumps in the cobalt planes than going back and forth or cross a gadolinium plane. This would mean that diffusion mainly occurs in the Co plane and that vacancies in the Gd planes are mainly trapped. Their presence is nevertheless necessary to make one oxygen escaping from time to time from the Co plane

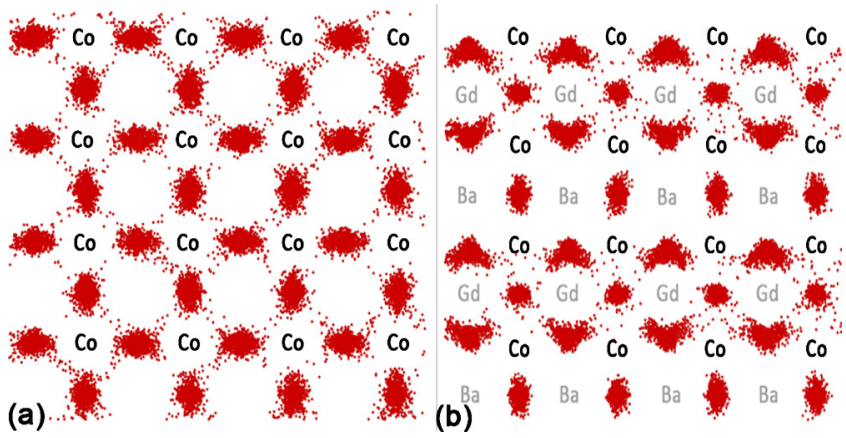

FIG. 3. (Color online) Calculated oxygen-density profiles in $\mathrm{GdBaCo}_{2} \mathrm{O}_{5.5}$ at $1200 \mathrm{~K}$ for interatomic potential set 2 along (a) the $c$-axis in the cobalt planes, and (b) the $b$-axis in the cobalt planes. 
leaving a highly diffusing oxygen vacancy in the Co plane. The first intuition that vacancies in Gd planes lead to an enhanced diffusion is then probably not fully correct. Actually, the diffusion in perovskite compounds involves nearestneighbor jumps between oxygen positions and can thus not be explained by the only consideration of vacancies in $\mathrm{Gd}$ planes. From these simulations, we indeed show that $\mathrm{Gd}$ planes serve as source-sink for oxygen vacancy rather than as real pathways.

In conclusion, MD simulations predict that oxygen transport in $\mathrm{GdBaCO}_{2} \mathrm{O}_{5.5}$ is strongly anisotropic with an activation energy of around $0.6 \mathrm{eV}$ in the temperature range of $1000-1600 \mathrm{~K}$. Oxygen atoms mainly diffuse along the cobalt planes with short hops into gadolinium planes and very seldom cross a barium plane. Meanwhile, most of oxygen vacancies are kept into gadolinium planes while some of them are moving along the cobalt planes to allow oxygen diffusion.

This work was performed using HPC resources from GENCI-[CCRT/CINES/IDRIS] (Project 2010x2010096468).

${ }^{1}$ B. C. H. Steele and A. Heinzel, Nature (London) 414, 345 (2001).

${ }^{2}$ J. Fleig, Annu. Rev. Mater. Res. 33, 361 (2003).
${ }^{3}$ A. Tarancón, A. Morata, G. Dezanneau, S. J. Skinner, J. A. Kilner, S Estradé, F. Hernández-Ramírez, F. Peiró, and J. R. Morante, J. Power Sources 174, 255 (2007).

${ }^{4}$ A. Tarancón, J. Peña-Martínez, D. Marrero-López, J. C. Ruiz-Morales, and P. Núñez, Solid State Ionics 179, 2372 (2008).

${ }^{5}$ A. Maignan, C. Martin, D. Pelloquin, N. Nguyen, and B. Raveau, J. Solid State Chem. 142, 247 (1999).

${ }^{6}$ W. Smith and T. Forester, J. Mol. Graphics 14, 136 (1996).

${ }^{7}$ W. Smith, Mol. Simul. 32, 933 (2006).

${ }^{8}$ PL_POLY code: www.ccp5.ac.uk/DL_POLY/.

${ }^{9}$ C. A. J. Fisher, M. Yoshiya, Y. Iwamoto, J. Ishii, M. Asanuma, and K. Yabuta, Solid State Ionics 177, 3425 (2007).

${ }^{10}$ D. Rupasov, A. Chroneos, D. Parfitt, J. A. Kilner, R. W. Grimes, S. Ya Istomin, and E. V. Antipov, Phys. Rev. B 79, 172102 (2009).

${ }^{11}$ G. Busker, A. Chroneos, and R. W. Grimes, J. Am. Ceram. Soc. 82, 1553 (1999).

${ }^{12}$ L. Minervini, M. O. Zacate, and R. W. Grimes, Solid State Ionics 116, 339 (1999).

${ }^{13}$ J. D. Gale and A. L. Rohl, Mol. Simul. 29, 291 (2003).

${ }^{14}$ A. Tarancón, S. J. Skinner, R. J. Chater, F. Hernández-Ramírez, and J. A Kilner, J. Mater. Chem. 17, 3175 (2007).

${ }^{15}$ D. S. Tsvetkov, V. V. Sereda, and A. Yu. Zuev, Solid State Ionics 180 , 1620 (2010)

${ }^{16}$ A. A. Taskin, A. N. Lavrov, and Y. Ando, Appl. Phys. Lett. 86, 091910 (2005).

${ }^{17}$ M.-B. Choi, S.-Y. Jeon, J.-S. Lee, H.-J. Hwang, and S.-J. Song, J. Power Sources 195, 1059 (2010). 